\title{
Validity of T-plate as a precondylar stopper in management of chronic recurrent temporomandibular joint dislocation: 5 years Original follow up \\ Article
}

\author{
Emad F. Essa, PhD
}

Lecturer of Oral \& Maxillofacial Surgery, Faculty of Dentistry, Tanta University, Egypt

\begin{abstract}
Introduction: The treatment of chronic recurrent temporomandibular joint dislocation is complex and controversial. There are many different surgical procedures that can limit the interincisal distance.
\end{abstract}

Objective: To evaluate the use of T-plate eminoplasty as a precondylar stopper in management of chronic recurrent temporomandibular joint dislocation with long-term follow up extended to 5 years.

Patients and methods: Eight patients (11 TMJs) were included in this prospective clinical study. All patients were complaining from either unilateral or bilateral chronic recurrent TMJ dislocation, they were managed with miniplates eminoplasty and evaluated clinically and radiographically postoperatively.

Results: Miniplates eminoplasty achieve the desired goals as return of interincisal distance to be within the normal range, the unilateral cases showed better tolerability and satisfaction than the bilateral cases and also the incidence of miniplate fractures in bilateral cases is more than that occur in unilateral cases.

Conclusion: Miniplate eminoplasty is an easy, reversible surgical technique used for the treatment of chronic recurrent TMJ dislocation with good results clinically and radiographically especially in unilateral cases than bilateral ones.

Key Words: Anterior Temporomandibular joint (TMJ) dislocation, Chronic recurrent, Eminoplasty, Management, TMJ disorders.

Received: 23 May 2018, Accepted: 21 October 2018

Corresponding Author: Emad F. Essa, Lecturer of Oral \& Maxillofacial Surgery, Faculty of Dentistry, Tanta University, Cairo, Egypt, Tel.: +2 01229018088, E-mail: emadessa1@gmail.com

ISSN: 2090-097X, May 2018, Vol. 9, No. 2

\section{INTRODUCTION}

Chronic recurrent temporomandibular joint (TMJ) dislocation is a condition where the condyle locks out anterior to the articular eminence to a position it cannot be self-reduced ${ }^{[1]}$ and it occurs when there is an excessive forward movement of the condyle beyond the ascending slope of the articular eminence ${ }^{[2]}$. The majority of cases occurring bilaterally but still it may affect one condyle ${ }^{[3]}$.

The morphology of the condyle, glenoid fossa, articular eminence, zygomatic arch and squamotympanic fissure greatly influence the displacement of the head of the condyle out of the glenoid fossa ${ }^{[4,5,6,7]}$.

TMJ dislocation can be partial (subluxation) or complete (luxation), bilateral or unilateral, acute, chronic protracted (long standing) or chronic recurrent ${ }^{[8,9]}$. Also, it may occur in different directions; anterior-medial, superior, medial, lateral or posterior dislocation. Anterior dislocations are the most common and occur due to displacement of the condyle anterior to the articular eminence of the temporal bone. The cause is either spontaneous or induced by trauma, forceful mouth opening from endotracheal intubation with laryngeal mask or tracheal tube, ENT/dental procedures, endoscopy, excessive mouth opening from yawning, laughing, vomiting and also during seizures ${ }^{[10,11,12]}$.

There are many different therapeutic approaches used to limit the massive forward movement of the condylar head. While treatment of acute TMJ dislocation requires only immediate manual repositioning of the condyle to avoid progressive muscular spasm, there are different modalities for treatment of chronic TMJ dislocation either conservative or surgical. The conservative method 
comprises a short period of intermaxillary fixation and restriction of mouth opening. The surgical method includes either minimally invasive procedures (e.g., injection of sclerosing solutions intracapsullary and intramuscular injection of botulinum toxin type A), or definitive surgical techniques including scarification of the temporalis tendon, myotomy of the lateral pterygoid muscle and eminoplasty either using bone grafting augmentation or application of titanium miniplates in the form of $\mathrm{L}$ or $\mathrm{T}$ shaped. Also reduction of the articular eminence is considered as another type of surgical treatment to permit a free movement of the condyle. Each form of these treatment modalities has its own advantages and disadvantages ${ }^{[13,14,15,16,17]}$.

Buckley and Terry ${ }^{[18]}$ described a technique using a bone plate fixed to the zygomatic arch to limit the condylar translation anteriorly for treating chronic mandibular dislocation, while Kent at the same year proved that the plate might lead to trauma of the condyle and reported a case in which Vitallium mesh fixed to the zygomatic arch caused the latter to fracture due to the constant pressure of the condyle.

Miniplate eminoplasty, described by Puelacher \& Waldhart ${ }^{[19]}$, considered to be a reliable technique to restrict condylar movement in patients with recurrent dislocation of the TMJ and habitual luxation if conservative treatment has failed and severe pain still persists. It is a technically easy extra-articular procedure which provides predictable functional results with a very low morbidity ${ }^{[19]}$.

The purpose of this research was to evaluate the clinical and radiographic results of T-plate eminoplasty as a precondylar stopper in management of chronic recurrent TMJ dislocation with long-term follow up extended to 5 years.

\section{PATIENTS \& METHODS}

This is a retrospective non-controlled clinical study that was carried out on eight patients (11 TMJs) and they were all suffering from either bilateral or unilateral chronic recurrent TMJ dislocation. All patients were selected and treated in the oral and maxillofacial surgery department, faculty of dentistry.

The inclusion criteria involved patients with at least five episodes of dislocations per month which annoying them, inability to perform normal jaw movements for speaking or eating, and patients with no response to previous conservative treatment modalities, such as a period of intermaxillary fixation.

Preoperative evaluation included a thorough history, clinical examination, and radiographic examination. The clinical examination addressed frequency of the dislocations, examination of TMJ and the muscles of mastication, registration of joint sounds (clicking, crepitation), evaluation of the range of different mandibular movements, and measurement of interincisal distance before and after the occurrence of dislocation (fig 1 A,B,C\&D ).

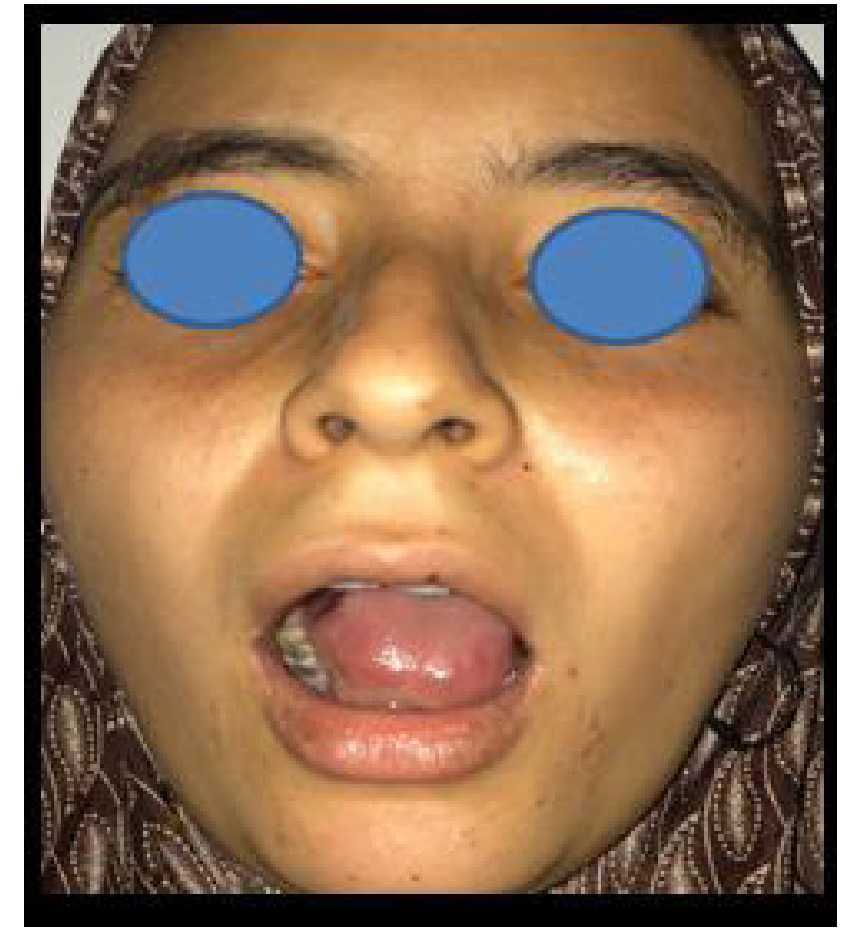

Fig. A1: Preoperative frontal photograph of case no 2 with bilateral TMJ dislocation.

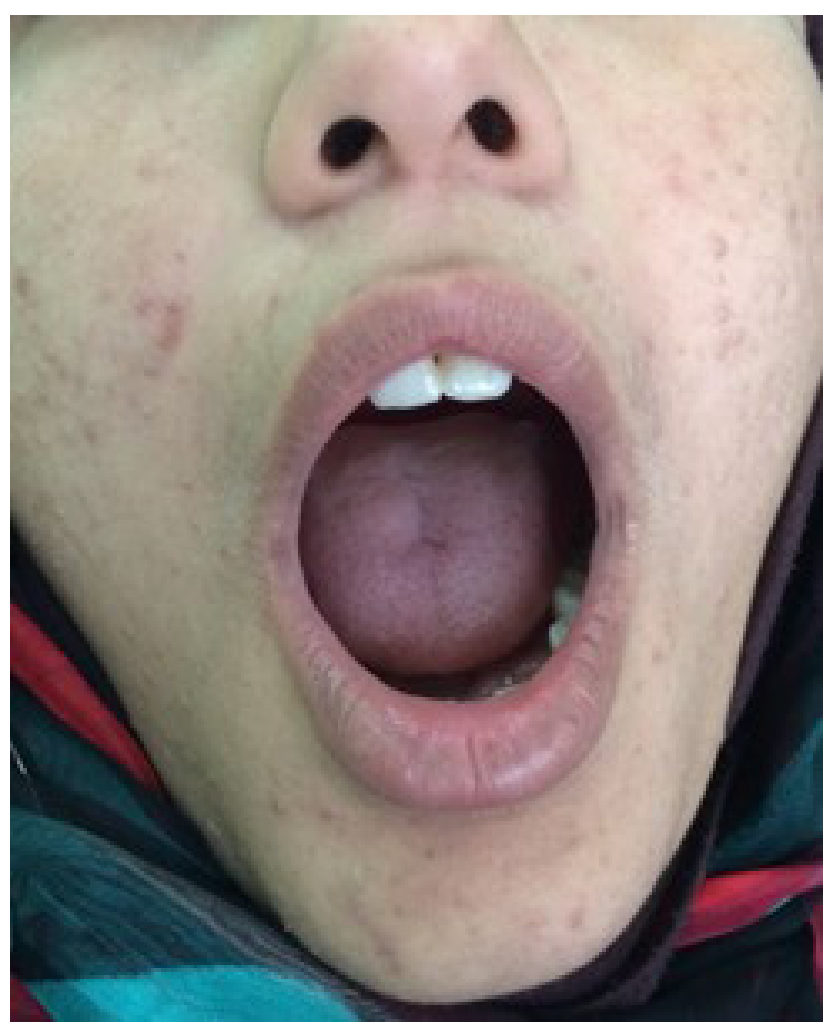

Fig. B1: Preoperative frontal photograph of case no 6 with LT TMJ dislocation. 


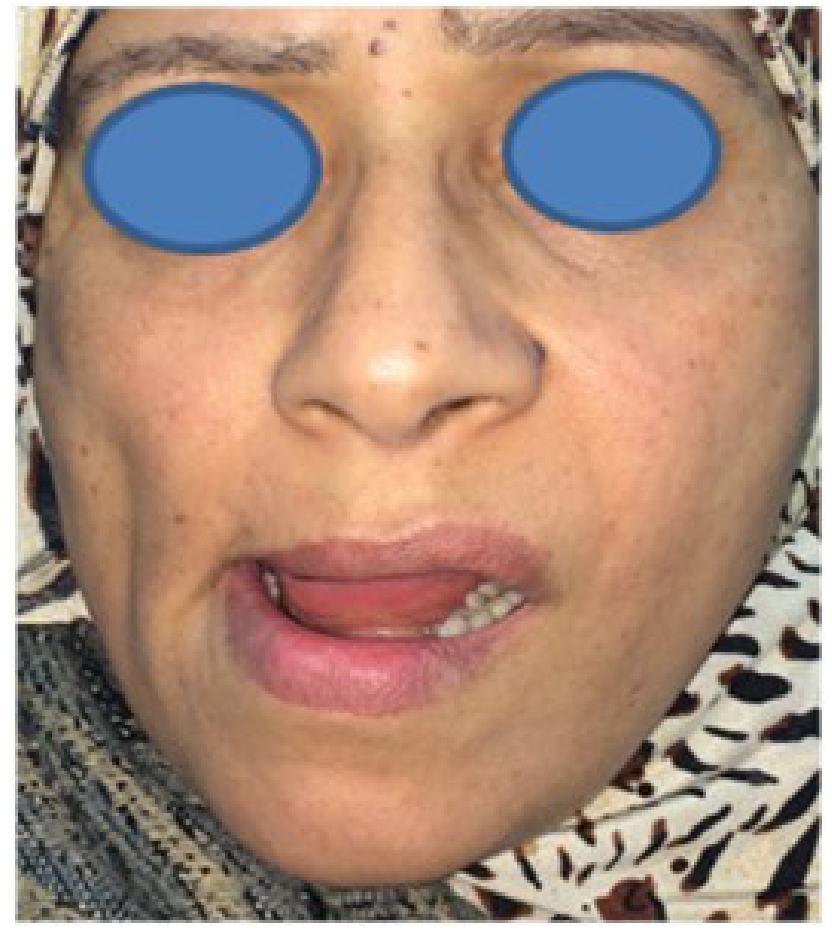

Fig. C1: Preoperative frontal photograph of case no 8 with LT TMJ dislocation.

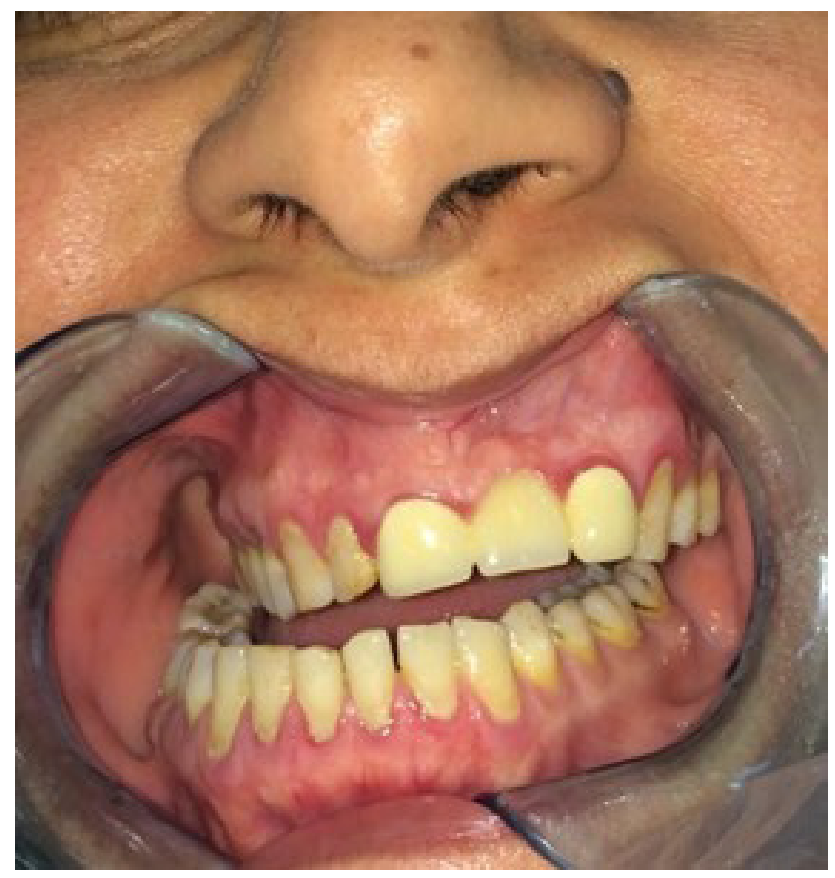

Fig. D1: Preoperative intraoral photograph of case no 8.

Radiographic examination in the form of panoramic radiographs, postroanterior views plus multi axial computed tomography was performed to determine the height of the articular eminence, shape of the condyle and the articulating disc space and degenerative changes (fig 2).
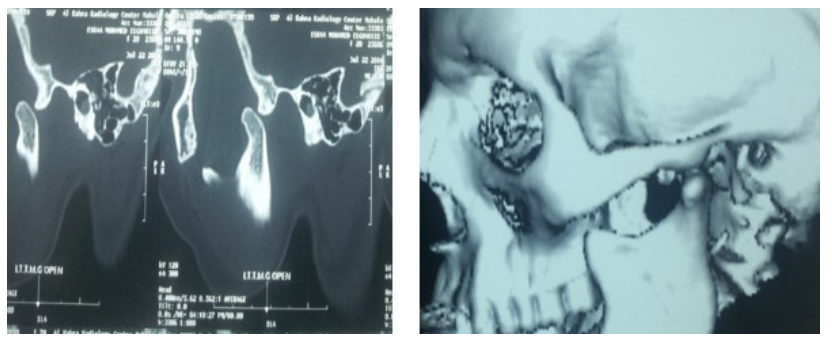

Fig. 2: Preoperative sagittal and 3D CT scan shown dislocated TMJ

The patients were followed up clinically at weekly basis during the 1 st month, then after 3, 6, and 12 months, then yearly up to 5 years.

\section{Surgical procedures:}

Under general anesthesia with nasoendotracheal intubation the temporomandibular joint was approached via the preauricular approach. After exposure and identification of the articular eminence, and in order to place the miniplate, the mouth opening was promoted up to the limit of condyle, reaching the lowest portion of articular eminence (as a reference for plate positioning), which led to approximately $35-40 \mathrm{~mm}$ opening. The T-shaped titanium miniplate was adapted and secured to the zygomatic arch and the short arm of the plate was fixed with three $7 \mathrm{~mm}, 2.0 \mathrm{~mm}$ diameter screws.

The vertical arm of the plate was positioned below and slightly anterior to the articular eminence serving as a precondylar stopper (Fig 3).
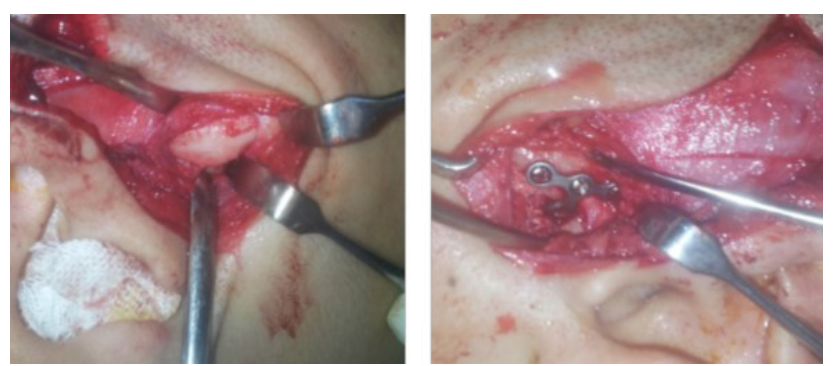

Fig. 3: Surgical exposure, identification of the articular eminence, adaptation and fixation of $\mathrm{T}$ plate as a precondylar stopper.

The jaw movements were then checked intraoperatively to confirm that the T-plate effectively restricts the anterior movement of the condyle and prevents its dislocation during maximum opening of the mouth using a mouth gage and any required adjustments were made. The preauricular incision was closed in layers without drain. The patients began gradual mandibular movements on the second postoperative day. A soft diet was ordered for 10 days.

\section{Postoperative clinical evaluation:}

1. Pain was assessed using a visual analogue scale 
(VAS) with a value of (0) indicating no pain and a value of (10) indicating severe pain and was compared to the preoperative records.

2. Interincisal distance was measured and recorded.

3. Facial nerve affection (temporal\& zygomatic branches) was examined and evaluated if present.

4. Patient's satisfaction was also recorded. A scale of zero to 10 with zero representing very unsatisfied and 10 representing very satisfied.
The postoperative radiographic examinations were performed immediately, after 3 months, 1 year, and 5 years.

\section{RESULTS}

A total of eleven TMJs of eight patients suffering from chronic recurrent TMJ dislocation underwent eminoplasty using T-plates were followed up for an average of five years after treatment.

Their age group ranged between 22-55 years with a mean of 35.5 years. Five patients were females $(62.5 \%)$ and three were males (37.5\%).

Table 1: Preoperative means and SD measurements of mouth opening and during follow up periods

\begin{tabular}{|c|c|c|c|c|c|c|c|c|}
\hline Measurements & Pre-dislocation & During dislocation & $\begin{array}{c}\text { Post-eminoplasty } \\
\text { Immediate }\end{array}$ & One month & $\begin{array}{l}\text { Three } \\
\text { month }\end{array}$ & $\begin{array}{l}\text { One } \\
\text { year }\end{array}$ & $\begin{array}{l}\text { Three } \\
\text { years }\end{array}$ & $\begin{array}{l}\text { Five } \\
\text { years }\end{array}$ \\
\hline \multicolumn{9}{|l|}{ Mouth opining } \\
\hline Mean & $25 \mathrm{~mm}$ & $42 \mathrm{~mm}$ & $30 \mathrm{~mm}$ & $37 \mathrm{~mm}$ & $38 \mathrm{~mm}$ & $37 \mathrm{~mm}$ & $35 \mathrm{~mm}$ & $37 \mathrm{~mm}$ \\
\hline $\mathrm{SD}$ & 5.5 & 10.5 & 11.6 & 10.4 & 10 & 10 & 6.7 & 9.5 \\
\hline$P$ value & & & $\geq 0.05$ & $\leq 0.05^{*}$ & $\leq 0.05^{*}$ & $\leq 0.05^{*}$ & $\leq 0.05^{*}$ & $\leq 0.05^{*}$ \\
\hline
\end{tabular}

T-plates were placed bilaterally in three patients (37.5\%) and unilaterally in the other five patients $(62.5 \%)$ who had only a unilateral chronic recurrent TMJ dislocation.

The healing of the preauricular skin incision showed uneventful course with inconspicuous scarring and without affection of the facial nerve branches (temporal or zygomatic) except in one case in which the affection was a temporary weakness that was completely recovered by the end of the 6th week and was attributed to excessive flap retraction during surgery.

Pain score in the preoperative periods during the attacks of dislocation as measured by the VAS was ranged from 6-9 with a mean of $7 \pm 1.8$ standard deviation (SD). This score was dramatically decreased one week postoperatively to be 3-6 with a mean of $4 \pm 1.3$ and completely disappeared after one month.

Regarding the interincisal distance (fig 4, table1) it was between $20-28 \mathrm{~mm}$ with a mean of $25 \mathrm{~mm} \pm 5.5$ predislocation while it was between $35-50 \mathrm{~mm}$ with a mean of $42 \mathrm{~mm} \pm 10.5$ during dislocation.

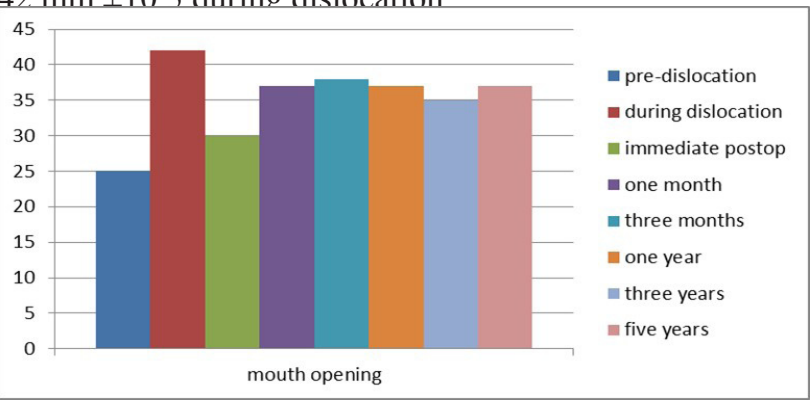

Fig. 4: Bargraph of the preoperative means of mouth opening and during follow up periods.

The immediate postoperative interincisal distance after one week ranged between $28-33 \mathrm{~mm}$ with a mean of 30 $\mathrm{mm} \pm 11.6$, with no statistically significant difference from the pre-dislocation of preoperative records. However, there was an increase in the interincisal distance after one month postoperative as it ranged from $35-42 \mathrm{~mm}$ with a mean of $37 \mathrm{~mm} \pm 10.4$, with statistically significant difference compared to the pre-dislocation measurements.

Three months, one year and Five years follow up showed almost normal mouth opening not less than $35 \mathrm{~mm}$ without recurrence of dislocation (fig 5 A,B,C\&D).

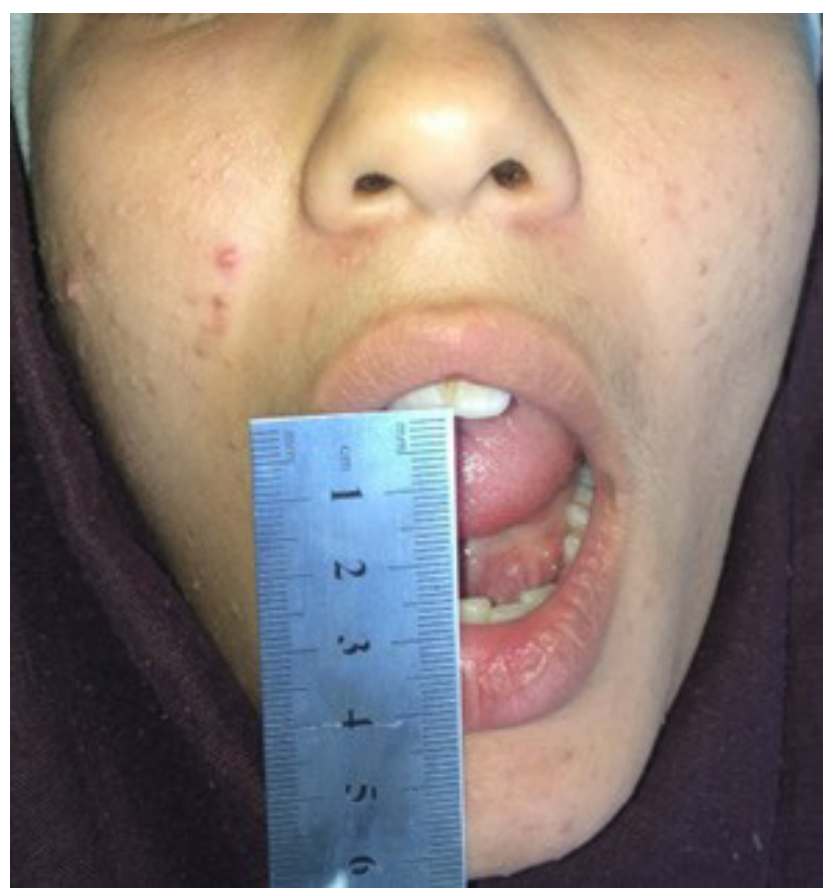

Fig. 5A: Immediate postoperative photograph showing adequate mouth opening. 


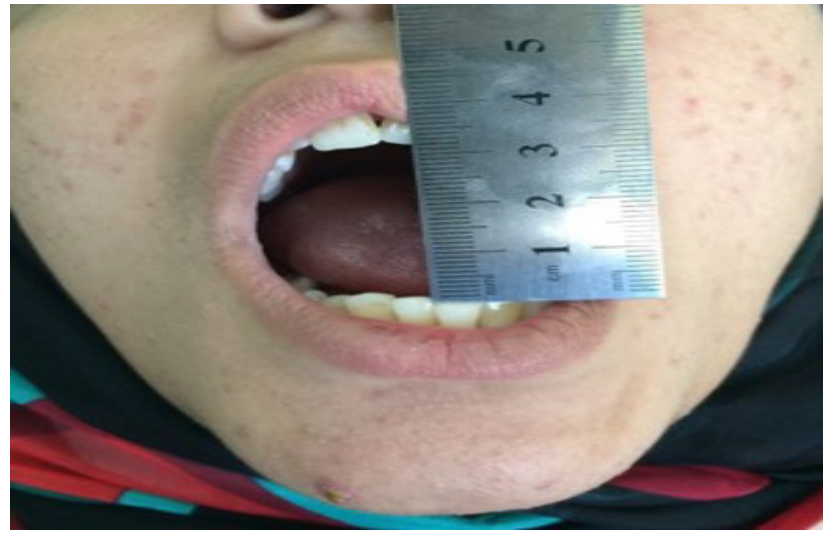

Fig. 5B: Five years postoperative photograph showing normal mouth opening.

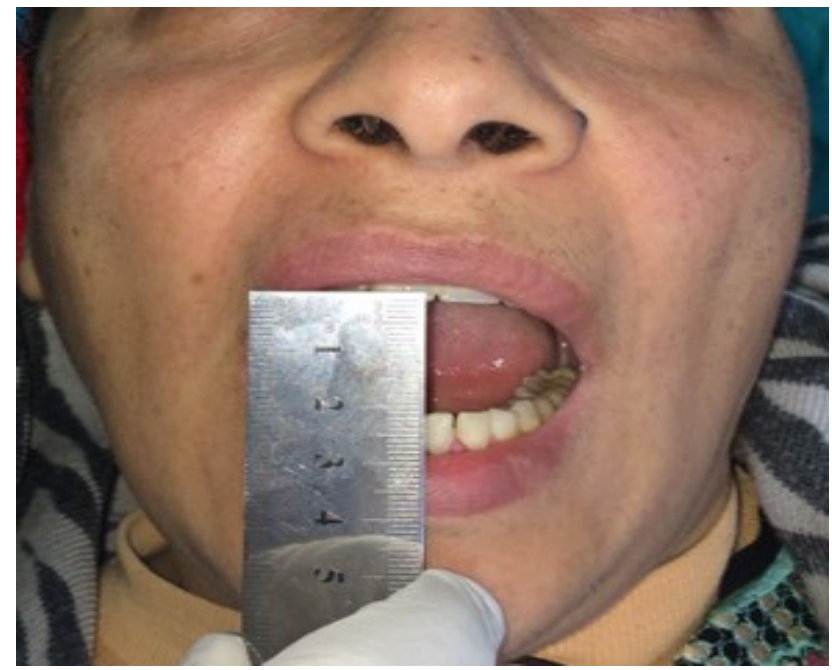

Fig. 5C: Immediate postoperative photograph of another case showing slight limited mouth opening.

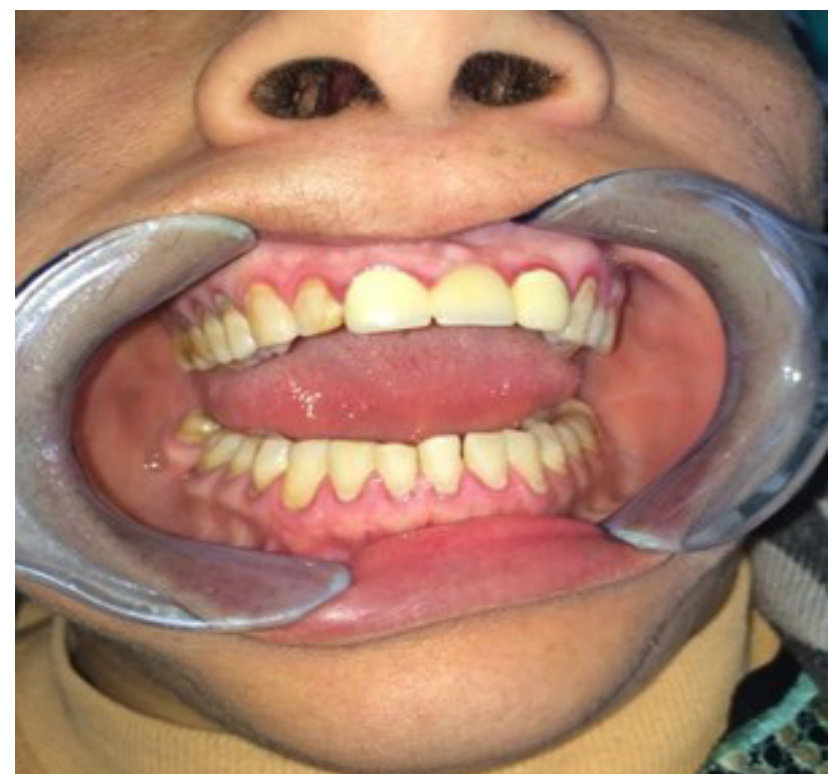

Fig. 5D: Five years postoperative mouth opening of the same case with adequate mouth opening.
Three joints out of eleven (27\%) showed recurrence of dislocation after three years, the cause was T-plates fractures.

Two joints from bilateral cases (33\%) showed unilateral fracture of the T-plate and only one joint in unilateral cases $(20 \%)$ showed T-plate fracture. Those three joints were managed via a second surgery for removal of the fractured plate and insertion of a new one, with uneventful postoperative course until 2 years (Fig 6)

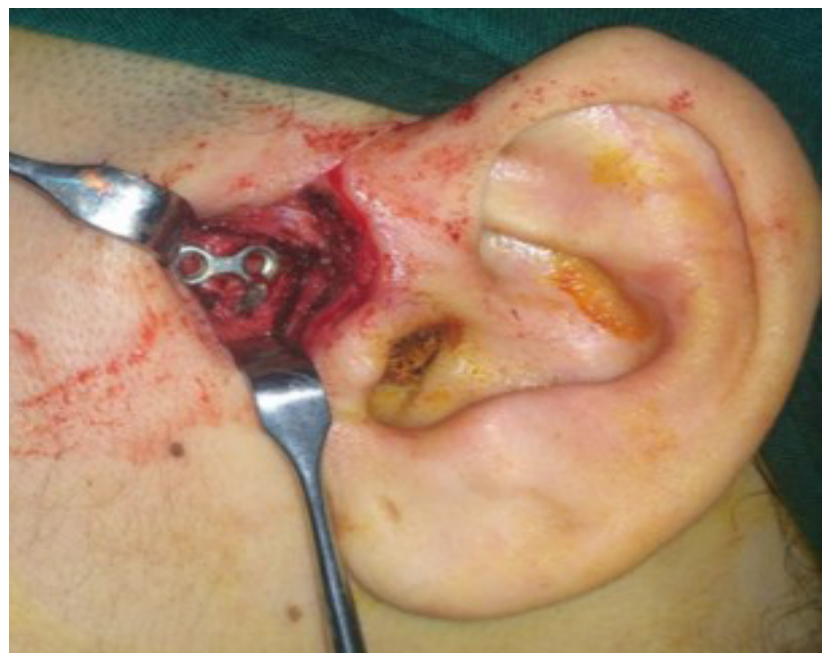

Fig. 6: Three years postoperative photograph showing fractured T-plate

Regarding patients' satisfaction, all patients were completely satisfied after surgical treatment during the whole follow up period. However, three patients showed some degree of dissatisfaction at the $3^{\text {rd }}$ year after fracture of the T-plate.

Radiographic results showed good positioning of the plates that appropriately augmenting the articular eminence with no affection or degenerative changes of both the condyle and the eminence. (Fig 7 A, B, C, D \& E)

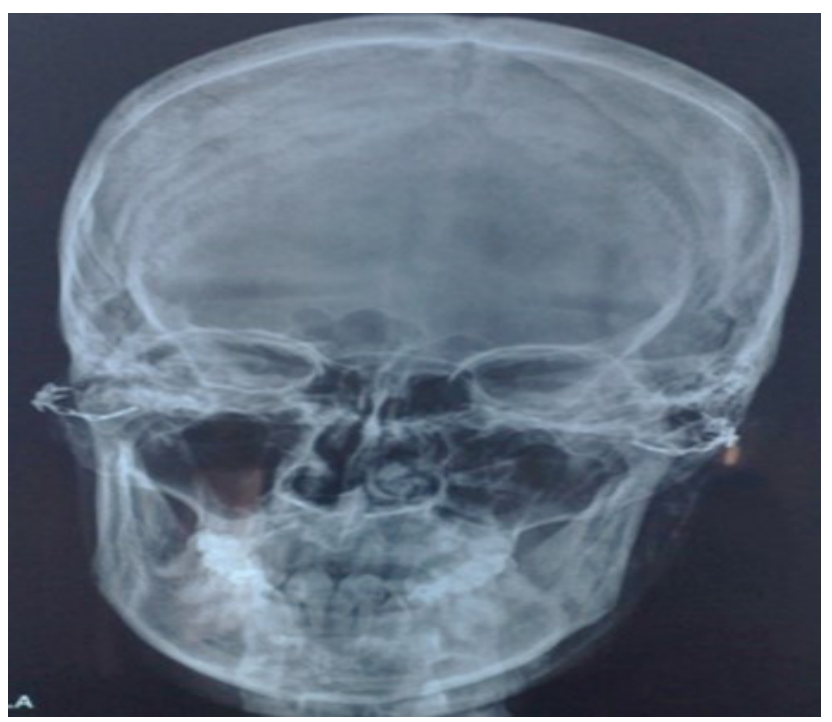

Fig. 7A: PA view of T-plate placed bilaterally as a precondylar stopper of case no 2 


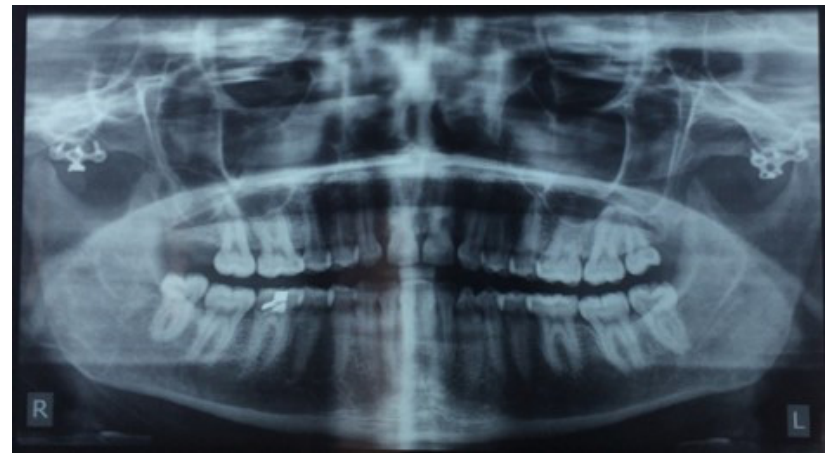

Fig. 7B: Panoramic radiograph of T-plate placed bilaterally of the same case

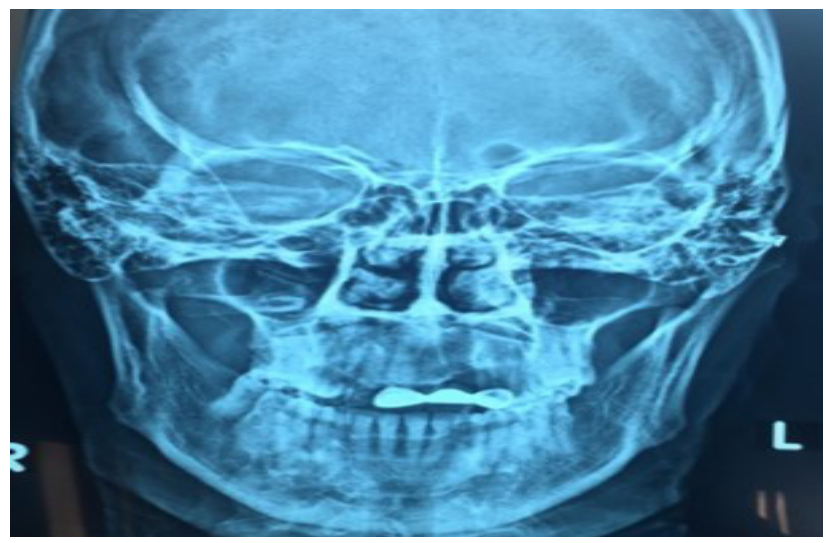

Fig. 7C: PA radiograph of LT T-plate placed unilaterally of case no 8

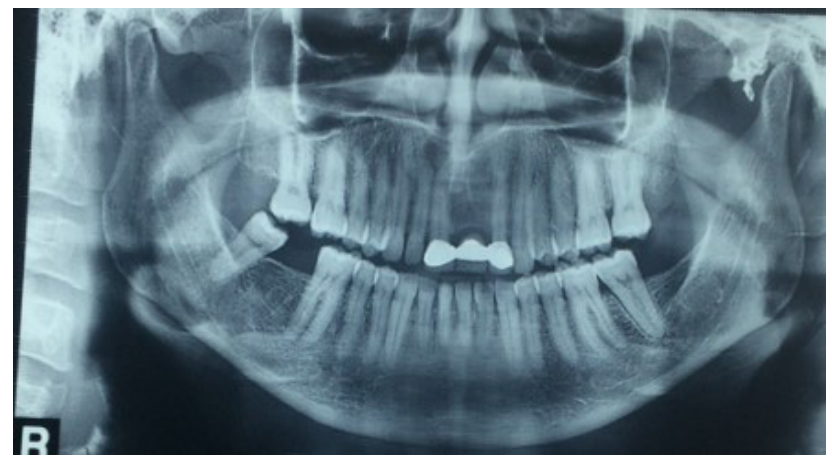

Fig. 7D: Panoramic radiograph of the same case showing T-plate as a precondylar stopper.

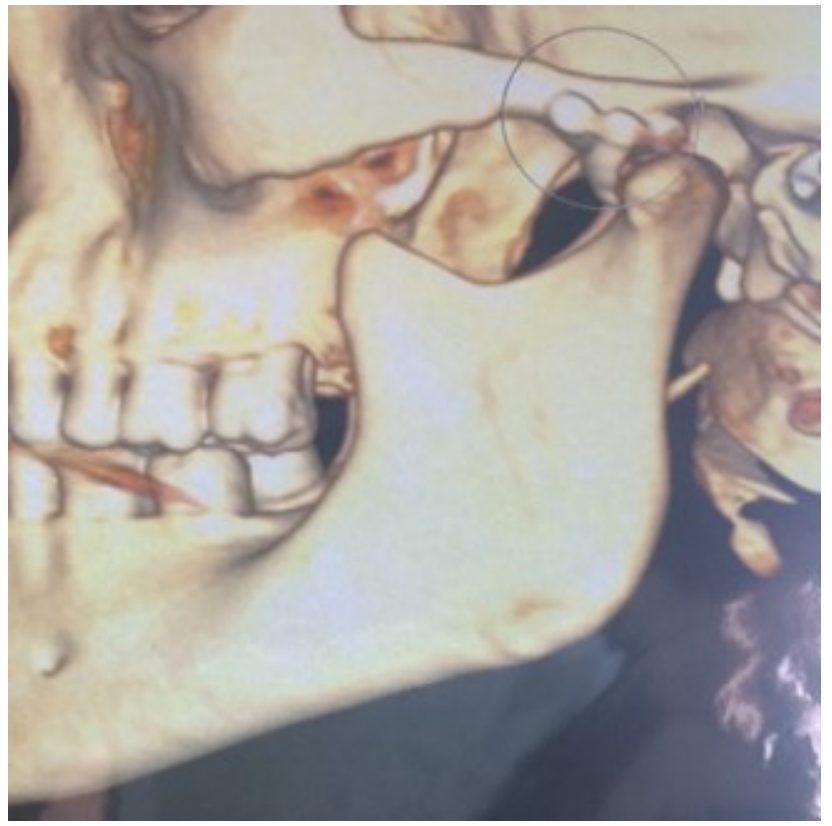

Fig. 7E: 3D CT scan showing adapted and fixed T-plates at the articular eminence.

\section{DISCUSSION}

Although recurrent luxation of the temporomandibular joint (TMJ) is considered as a rare condition, it still represents about $3 \%$ of all articular body luxations ${ }^{[20]}$. The highest incidence of recurrent TMJ luxation is reported in females similarly to other TMJ disorders; this is in agreement with the present study as female patients represent $62.5 \%$ from the total sample.

The major complaint of patients with chronic recurrent TMJ dislocation is the condyle being locked anterior to the articular eminence itself causing pain, because it leads to a stretching of articular components ${ }^{[4]}$. This is in accordance with the findings of present study which illustrate an increase in pain score after dislocation and a marked reduction after treatment.

It was reported that chronic prolonged or chronic recurrent TMJ dislocation is best treated surgically ${ }^{[21]}$. Different surgical techniques had been described in the literature based on either removal of the mechanical obstacle in the condylar path in the form of eminectomy or creation 
of a mechanical obstacle in the condylar path, such as positioning the disc anterior to the condyle, downfracturing of the zygomatic arch and fixation medial to the eminence, or insertion of implants into the eminence ${ }^{[21,22]}$. Each has its own advantages and disadvantages.

In a comparative study of eminectomy and use of bone miniplate in the articular eminence for the treatment of recurrent temporomandibular joint dislocation done by Cardoso et $\mathrm{a}^{[2]}$ and Pogrel ${ }^{[23]}$, they reported that out of 15 cases managed via unilateral eminectomy 11 cases presented with deviation to the operated side during mouth opening.

Also eminectomy may lead to hypermobility, which may result in a degeneration of the TMJ and an excessive mouth opening ${ }^{[4]}$. Accordingly, the selected treatment in this study was placement of a titanium miniplate in the articular eminence as a precondylar stopper aiming to increase the articular eminence height which prevents massive forward movement of the condyle, thereby avoiding its displacement according to Puelacher and Waldhart ${ }^{[19]}$.

The pre-auricular approach was selected to expose the articular eminence region in the present study which is in agreement with Puelacher and Waldhart ${ }^{[19]}$. All patients had no facial verve affection except one patient who showed some degree of weakness from flap retraction, preservation of the facial nerve branches was due to the process of dissection that was subperiosteal along the lateral surface of the zygomatic arch avoiding the temporal and zygomatic branches of the facial nerve, as these branches are located within the substance of the retracted flap, this is in accordance with Ellis and Zide ${ }^{[24]}$.

In the current study, eminoplasty using T-shaped miniplates showed some advantages as being a reversible, less invasive method, quick as it takes less time and can be modified during surgery. On the other hand, there is still the disadvantage of the possibility of plate fracturing that requires a second operation for removal of the plate and choice of another treatment. Fatigue of the plate material during bending and adaption to the articular eminence during surgery could explain the cause of plate fracture, as also explained in previous studies ${ }^{[22]}$.

One of the main important results of this research is to answer the question when to do eminoplasty using miniplates? And how to select the patients suitable for this surgical technique regarding site, age, and gender. By proper patient selection, this surgical technique with its associated advantages could be performed with a high success rate, neglected morbidities, and a long duration of appropriate TMJ function.

In answering the previous questions, the results of this study demonstrate that miniplates eminoplasty is not the proper treatment in bilateral chronic recurrent TMJ dislocation, which is in agreement with the findings of Kuttenberger and Hardt ${ }^{[22]}$.
This is evidenced by the increased incidence of plate breakage in the bilateral cases of this study within an average of three years. This finding could be explained by the inability of the plates to tolerate the muscular and condylar forces exerted simultaneously from both sides during normal daily functions of TMJ over years.

\section{CONCLUSION}

T-shaped miniplates eminoplasty has the advantages of being effective in treating TMJ chronic dislocation, as being less invasive, quick method, can be modified during surgery and also a reversible technique.

To guarantee a long duration of successful results of this technique, it is recommended to be used only in unilateral cases of TMJ chronic dislocation.

\section{CONFLICT OF INTEREST}

This paper has no conflict of interest.

No fund.

\section{ACKNOWLEDGMENT}

We would like to express gratitude to all members of Oral and Maxillofacial Surgery Department, Faculty of Dentistry, Tanta University, for their great help and unlimited support.

\section{REFERENCES}

1. Undt G, KImmer C, Piehlinger E,et al. Treatment of recurrent mandibular dislocation, part I: Leclerc blocking procedure. Int J Oral Maxillofac Surg 1997; 26: 92-97.

2. Cardoso AB, Vasconcelos BC, Oliveira DM. Comparative study of eminectomy and use of bone miniplate in the articular eminence for the treatment of recurrent temporomandibular joint dislocation. Braz J Otorhinolaryngol 2005;71:32

3. Huang IY, Chen CM, Kao YH, Chen CM, et al. Management of long-standing mandibular dislocation. Int $\mathrm{J}$ Oral Maxillofac Surg 2011;40(8):810-4.

4. Gay-Escoda C. Eminectomy associated with redirectioning of the temporal muscle for treatment of recurrent TMJ dislocation. J Craniomaxillofac Surg 1987; 15(6):355-8.

5. Güven O. Review Inappropriate treatments in temporomandibular joint chronic recurrent dislocation: presenting three particular cases. J Craniofac Surg 2005; 16(3):449-52.

6. Vasconcelos BC, Porto GG, Neto JP, et al. Review Treatment of chronic mandibular dislocations by eminectomy: follow-up of 10 cases and literature review. Med Oral Patol Oral Cir Bucal 2009; 14(11):e593-6. 
7. Medra AM, Mahrous AM: Glenotemporal osteotomy and bone grafting in the management of chronic recurrent dislocation and hypermobility of the temporomandibular joint. Br J Oral Maxillofac Surg 2008; 46(2):119-22.

8. Gao C. Long-term results of the treatment of mandibular condyle Fracture. Zhonghua Kou Qiang Yi Xue Za Zhi 1989, 24(4):228-9, 255.

9. Mangi Q, Ridgway PF, Ibrahim Z,et al. Dislocation of the mandible. Surg Endosc 2004; 18(3):554-6.

10. Lowery LE, Beeson MS, Lum KK. The wrist pivot method, a novel technique for temporomandibular joint reduction. J Emerg Med 2004; 27(2):167-70.

11. Thangarajah $\mathrm{T}, \mathrm{McCulloch} \mathrm{N}$, Thangarajah $\mathrm{S}$, et al. Bilateral temporomandibular joint dislocation in a 29-year-old man: a case report. J Med Case Reports 2010; 4:263.

12. Rattan V, Arora S. Prolonged temporomandibular joint dislocation in an unconscious patient after airway manipulation. Anaesth Analg 2006;102:1294

13. Bakardjiev A. Treatment of chronic mandibular dislocations by bone plates: Two case reports. J Craniomaxillofac Surg 2004; 32:90

14. Martínez-Pérez D, García Ruiz-Espiga P. Recurrent temporomandibular joint dislocation treated with botulinum toxin: Report of 3 cases. J Oral Maxillofac Surg 2004; 62:244

15. Laskin DM: Myotomy for management of recurrent and protracted mandibular dislocation. Trans Int Conf Oral Surg 1973;4:264.

16. Gould JF. Shortening of the temporalis tendon for hypermobility of the temporomandibular joint. J Oral Surg 1978;36:781,
17. Oztan HY, Ulusal BG, Turegun M, et al. Titanium screw implantation to the articular eminence for the treatment of chronic recurrent dislocation of the temporomandibular joint. Int J Oral Maxillofac Surg $2005 ; 34: 921$

18. Buckley MJ, Terry BC: Use of bone plates to manage chronic mandibular dislocation: report of case. J Oral Maxillofac Surg 1988;46: 998-1002,

19. Puelacher WC, Waldhart E. Miniplate eminoplasty: a new surgical treatment for TMJ-dislocation. J Cranio maxillofac Surg 1993; 21: 176-178.

20. Lovely FW, Copeland RA. Reduction eminoplasty for chronic recurrent luxation of the temporomandibular joint. J Can Dent Assoc.1981;47:179-84.

21. Sato J, Segami N, Nishimura M, et al: Clinical evaluation of arthroscopic eminoplasty for habitual dislocation of the temporomandibular joint: Comparative study with conventional open eminectomy. Oral Surg Oral Med Oral Pathol Oral Radiol Endod 2003;95:390,

22. Kuttenberger JJ, Hardt N: Long-term results following miniplate eminoplasty for the treatment of recurrent dislocation and habitual luxation of the temporomandibular joint. Int J Oral Maxillofac Surg 2003;32:474,

23. Pogrel MA. Articular eminectomy for recurrent dislocation. $\mathrm{Br} \mathrm{J}$ Oral Maxillofac Surg. 1987;25:237-43.

24. Ellis E, Zide MF. Approaches to the temporomandibular joint, in Surgical Approaches to the Facial Skeleton (ed 1). Philadelphia, PA, Lippincott Williams \& Wilkins, 1995; pp 163- 185 